\title{
Three-Dimensional Graphene Interconnected Structure, Fabrication Methods and Applications: Review
}

\author{
Bagoole O, Rahman M, Younes H, Shah S and Al Ghaferi A*
}

Department of Mechanical and Materials Engineering, Masdar Institute of Science and Technology, P.O Box 54224, Abu Dhabi, United Arab Emirates

\begin{abstract}
Enormous amounts of research and development are currently underway in the arena of improving threedimensional graphene and graphene oxide networks for use as foams, sponges and aerogels for a wide range of applications. The underlying reason for the interest in 3D grapheme can be attributed to the splendid intrinsic and extrinsic properties brought as a result of the 3D porous structures which has given rise to high specific surface areas, good mechanical strength, fast mass and electron movement. Therefore a review about the present modes of fabrication, material properties and the applications of 3D grapheme with strong emphasis on highly efficient graphene sponges and graphene foams is expounded. Following on from this, a concrete understanding of the fabrication of functionalized graphene aerogel for use in oil water separation will be addressed. To add on, the superiority of threedimensional (3D) graphene based macro porous architectures, as an absorbent in comparison to various sorbent materials will be scrutinized. Furthermore, it was concluded that although large amounts of research and developments have been achieved thus far, there is still some room for improvement. In fact the benefits of these improvements will be applicable in a wide range of applications ranging from: high sensitivity gas detectors, super capacitors, lithium ion batteries, oil-water separators to name a few.
\end{abstract}

Keywords: GF (Graphene foam); GS (Graphene sponge); GO (Graphene oxide)

\section{Introduction}

Since the discovery of graphene, in 2004 at the University of Manchester by Kostya Novoselov and Andre Geim by removing some flakes from a lump of bulk graphite, we have witnessed tremendous efforts by the research community to the development of graphene derivatives in the form of graphene sponge, graphene aerogels and graphene foams. Researchers are trying to improve the intrinsic properties of graphene derivatives by tuning the fabrication parameters. Graphene is an allotrope of Carbon in the structure of a plane of $\mathrm{sp}^{2}$ hybridised atoms with a molecule bond length of 0.142 nanometres [1] and shows numerous unique and invaluable properties, for instance, high mechanical strength [2,3], high thermal conductivity and stability [4].

Graphene as a potential candidate for a variety of real life applications such as supercapacitors [5], absorbents [6], and sensors [7] can be attributed to the unique and tunable graphene properties. Great efforts and investments over the past years have yielded great scientific advances in the research and development of 3D graphene porous micro/Nano-architectures, it is imperative to be aware of why it is necessary and beneficial to have graphene in a $3 \mathrm{D}$ form.

Graphene in 3D form is expected to overcome several key barriers restricting the further development of supercapacitors [5], sensors [7] and absorbents [6]. From the scientific point of view, the first major advantage of graphene in $3 \mathrm{D}$ form over layered structured where graphene sheets restack themselves and agglomerate [8-11] due to the presence of strong van der Waals interactions and high inter-sheet junction contact resistance [12] is reduced contact resistance and better mechanical properties. This phenomenon or occurrence leads to a suppression of the excellent intrinsic properties of graphene, that is to say lower specific surface area and lower mechanical strength [13]. These drawbacks of single atom graphene mean that efforts to carefully engineer graphene whereby graphene sheets are bonded to one another in order to construct a three-dimensional porous structure and thus prevent re-stacking and consequently maintain the excellent desirable intrinsic properties [14].
Secondly, 3D graphene can be manufactured to have differing morphologies and material properties, for example graphene foams are normally synthesised with Nickel foam as a material template [11,15-18] and thus graphene foam possesses a continuous and interconnected macro porous structure mirrored by the Nickel foam [19]. On the other hand, graphene sponges are named as such because of the highly efficient recyclable absorption and the graphene sheets are nearly parallel to each other [20]. As for graphene aerogels, these can be fabricated by making use of the Hummer's method [21-23] to produce Graphene oxide ( $\mathrm{GO}$ ) and then reducing it to form a much better cross-linked graphene hydrogel (GH) and subsequently followed by freeze-drying [24].

This review addresses both direct synthesis and Graphene Oxide reduction procedures for the fabrication of three-dimensional graphene materials such as chemical vapour deposition and template assisted growth respectively. The material properties of the fabricated graphene derivatives fabricated via different synthesis methods are listed in Table 1, with specific surface areas, density and pore sizes shown. Therefore, section 3 presents the work carried out to fabricate 3D graphene structures by various academics in literature, whereas section 4 outlines the properties of the 3D structures and what influences them. Lastly, section 5 presents the various applications of these 3D graphene structures. Finally, we conclude our personal perspectives on the future outlook of possible further areas of research.

*Corresponding author: Amal Al Ghaferi, Mechanical and Materials Engineering Department, Masdar Institute of Science and Technology, P.O Box 54224, Abu Dhabi, United Arab Emirates, Tel: 97128109103; E-mail: aalghaferi@masdar.ac.ae

Received: March 17, 2017; Accepted: March 25, 2017; Published: April 01, 2017

Citation: Bagoole O, Rahman M, Younes H, Shah S, Al Ghaferi A (2017) Three-Dimensional Graphene Interconnected Structure, Fabrication Methods and Applications: Review. J Nanomed Nanotechnol 8: 438. doi: 10.4172/21577439.1000438

Copyright: @ 2017 Bagoole O, et al. This is an open-access article distributed under the terms of the Creative Commons Attribution License, which permits unrestricted use, distribution, and reproduction in any medium, provided the original author and source are credited. 
Citation: Bagoole O, Rahman M, Younes H, Shah S, Al Ghaferi A (2017) Three-Dimensional Graphene Interconnected Structure, Fabrication Methods and Applications: Review. J Nanomed Nanotechnol 8: 438. doi: 10.4172/2157-7439.1000438

Page 2 of 8

\begin{tabular}{|c|c|c|c|c|c|}
\hline Synthesis method & $\begin{array}{l}\text { Specific surface } \\
\text { area }\left(\mathrm{m}^{2} / \mathrm{g}\right)\end{array}$ & Pore structure & $\begin{array}{l}\text { Electrical conductivity } \\
(\mathrm{S} / \mathrm{cm})\end{array}$ & Density $\left(\mathrm{mg} / \mathrm{cm}^{3}\right)$ & Applications \\
\hline $\begin{array}{l}\text { GS/Self-assembly of GO, hydrothermal } \\
\text { treatment, freeze-drying }\end{array}$ & 423 & Long axis is $750-620 \mu \mathrm{m}$ & & $1 \pm 25$ & $\begin{array}{l}\text { Sorbent for oils and organic } \\
\text { solvents; }\end{array}$ \\
\hline $\begin{array}{l}\text { GS/Self-assembly of } \mathrm{GO} \text { with } \mathrm{Fe}_{3} \mathrm{O}_{4} \text {, } \\
\text { hydrothermal treatment, freeze-drying }\end{array}$ & 114.5 & Ranging from 6-100 nm & & $\leq 5$ graphene layers & Lithium ion batteries \\
\hline $\begin{array}{l}\text { Crosslinking of GO sheets followed by } \\
\text { chemical cross-linking, super-critical } \\
\text { drying and thermal reduction }\end{array}$ & 584 & $\begin{array}{l}\text { Large Pore volume of } 2.96 \\
\qquad \mathrm{~cm}^{3} / \mathrm{g}\end{array}$ & $1 \times 10^{2}$ & 10 & $\begin{array}{l}\text { Catalysis, sensing and } \\
\text { energy storage }\end{array}$ \\
\hline $\begin{array}{l}\text { Self assembly of GO in a noble salt } \\
\text { and glucose, hydrothermal treatment, } \\
\text { freeze-drying }\end{array}$ & & & $2.5 \times 10^{-3}$ & 30 & Catalysis \\
\hline $\begin{array}{c}\text { Ni foam Template assisted synthesis of } \\
\text { GF, add PDMS prepolymer }\end{array}$ & 850 & $\begin{array}{l}\text { Porosity is approximately } \\
99.7 \%\end{array}$ & 7 & 3 Graphene layers & Flexible conductors \\
\hline $\begin{array}{c}\text { Assembly of GO sheets onto PU-foam } \\
\text { by dip-coating, heating to produce GF } \\
\text { sponge }\end{array}$ & & Porosity of $99.8 \%$ & 40 & 8.8 & Sensors \\
\hline $\mathrm{GH} /$ hydrothermal & & Pore size of $0.1-7 \mu \mathrm{m}$ & $5 \times 10^{-3}$ & & Sensors, catalysis \\
\hline
\end{tabular}

Table 1: Showing the properties of 3D graphene materials produced by different synthesis routes.

\begin{tabular}{|c|c|c|c|c|}
\hline Synthesis method & Specific surface area & Specific capacitance & Number of cycles & Applications \\
\hline $\begin{array}{l}\text { GS/Self-assembly of GO, freeze-drying. } \\
\text { Nitrogen doping in autoclave }\end{array}$ & & $170 \mathrm{Fg}^{-1}$ at $0.5 \mathrm{Ag}^{-1}$ & 10,000 at $10 \mathrm{Ag}^{-1}$ & Super capacitors \\
\hline $\begin{array}{l}\text { Reduced multilayer graphene oxide through } \\
\text { reduction of GO }\end{array}$ & & $247 \mathrm{Fg}^{-1} / 281 \mathrm{nAcm}^{-2}$ & & Ultrathin capacitors \\
\hline $\begin{array}{c}\text { Hummer's method to produce GO, followed by } \\
\text { autoclaving with HMTA. }\end{array}$ & & $737 \mathrm{Fg}^{-1}$ at $1 \mathrm{Ag}^{-1}$ & 3000 at $4 \mathrm{Ag}^{-1}$ & Super capacitors \\
\hline $\begin{array}{l}\text { Self assembly of GO produced by Hummer's } \\
\text { method }\end{array}$ & $2400 \mathrm{~m}^{2} / \mathrm{g}$ & $200 \mathrm{Fg}^{-1}$ & $2.5 \times 10^{-3}$ & Supercapacitors \\
\hline
\end{tabular}

Table 2: Showing the properties of 3D graphene structures fabricated for supercapacitor application.

\section{Synthesis}

There are various synthesis methods for three-dimensional graphene namely: Direct synthesis of 3D Graphene, Assembly of Graphene Oxide sheets and template assisted assembly. These three methods can be correlated to the different applications of 3D Graphene. Take for instance, 3D Graphene fabricated by Chemical Vapour Deposition has been found to exhibit high energy density and long life span when used as anodes in Lithium-Sulfur batteries. However, this CVD method of synthesis has acrucial obstacle in that it is a very expensive fabrication technique which requires firstly, the need of a pure Nickel foam to act as a catalyst and secondly etching the Nickel foam carefully to leave a free standing graphene foam. This hampers mass production. Furthermore, in this section of the report we shall address the work carried out by authors on the three synthesis routes. This will benefit the reader because the synthesis routes and their main applications are carefully correlated.

\section{Direct synthesis of 3d graphene}

Template-assisted chemical vapour deposition growth: Chemical Vapour Deposition (CVD) is one of the ways to grow 3D grapheme [25-32]. It entails using pre-fabricated 3D metal substrates for example $\mathrm{Ni}$ foam. The Ni foam in this instance acts as both a catalyst and a template. Chen and his team for example managed to use CVD to synthesise graphene foam using Nickel foam as a template [19]. Porous Nickel foam was subjected to prolyzed methane gas $\left(\mathrm{CH}_{4}\right)$ at $1000^{\circ} \mathrm{C}$ and ambient pressure at constant rates. Following this a very thin film of polymethyl methacrylate (PMMA) was deposited onto the graphene film surface to serve as protection from the etchant. Then the Nickel foam with deposited graphene film was etched in Hydrochloric acid $(\mathrm{HCl})$ or $\mathrm{FeCl}_{3}$ solution to remove the Nickel. Next, hot acetone was employed for the purpose of removing the PMMA to subsequently give birth to freestanding graphene foam (Table 2).
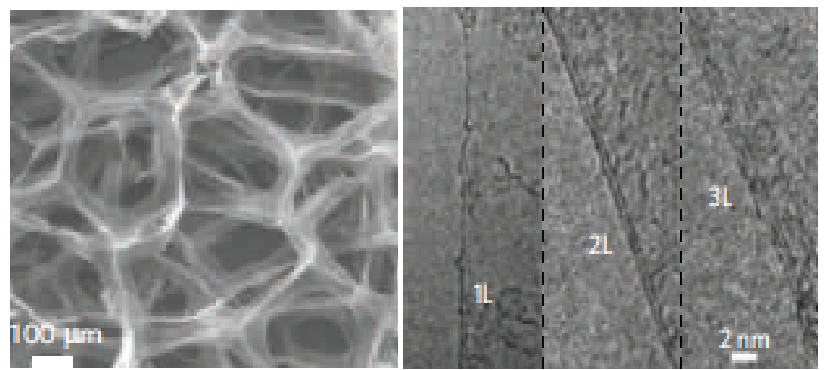

Figure 1: Showing the interconnected 3D micro porous structure of graphene foam [19].

This method produced high quality 3D graphene foam which was continuous and all graphene sheets interconnected just like the Nickel foam skeleton. An SEM micrograph of the 3D graphene foam can be seen below.

It was appreciated that the surface area of the graphene foam depended on the relative number of layers in the graphene film. A three layer graphene film could have a surface area as high as $850 \mathrm{~m}^{2} / \mathrm{g}$ with inter layer spacing of $0.34 \mathrm{~nm}$ as seen in Figure 1 [19]. It is important to note that the pore size has an effect on the material properties of the 3D graphene structure. This is crucial because during the Nickel foam graphene CVD fabrication, the graphene foam takes on a pore size in the range of hundreds of micrometres in diameter. It is for this reason that various templates have been experimented on-these include $\mathrm{ZnO}$, $\mathrm{MgO}, \mathrm{AAO},[33-35]$ metal nanostructures and various metallic salts.

Guoqing Ning et al. [34] reported the growth of nanomesh 3D graphene after subjecting a porous $\mathrm{MgO}$ layer to $\mathrm{CH}_{4}$ carbon source in a Chemical Vapour Deposition process to produce one to two graphene layers and specific surface area of $1654 \mathrm{~m}^{2} \mathrm{~g}^{-1}$. This is in stark contrast 
to the $850 \mathrm{~m}^{2} \mathrm{~g}^{-1}$ obtained by using the Nickel foam [19]. Furthermore, Guoging Ning et al. achieved pore diameters of $10 \mathrm{~nm}$. The pore size can also be tuned by varying two key parameters during the CVD process; time and temperature. Mingwei Zhou et al. [36] prepared a nanoporous Ni substrate having a thickness of ca. $30 \mu \mathrm{m}$ and average pore size of ca. $10 \mathrm{~nm}$ and were able to use as a sacrificial template in the fabrication of $3 \mathrm{D}$ nanoporous graphene sheets with tunable pore sizes ranging from ca.100 $\mathrm{nm}$ to ca. $2.0 \mu \mathrm{m}$.

Over and above this, we can also use other templates during Chemical Vapour Deposition other than Nickel. Hong et al. [37] investigated the template assisted growth of $3 \mathrm{D}$ graphene using porous $\mathrm{Al}_{2} \mathrm{O}_{3}$ ceramic. The AAO template is known to be regular and is composed of a 1D channel tray, pore size of approximately $95 \mathrm{~nm}$. The graphene was grown at a temperature of $1200^{\circ} \mathrm{C}$ for about half an hour under the flow of Argon, Hydrogen and Methane gases. By analysing the formation mechanism of the graphene onto the porous $\mathrm{Al}_{2} \mathrm{O}_{3}$ it was reported that there is a carbothermic reduction that takes place at the $\mathrm{Al}_{2} \mathrm{O}_{3}$ surface which initiates nucleation and growth of graphene. An interconnected macroporous framework of graphene sheets was observed and as a result, the graphene/ $\mathrm{Al}_{2} \mathrm{O}_{3}$ composite $\left(\mathrm{G}-\mathrm{Al}_{2} \mathrm{O}_{3}\right)$ exhibited a low sheet electrical resistance. A thermal conductivity of $8.28 \mathrm{Wm}^{-1} \mathrm{~K}^{-1}$, [37] implying that the material has a highly thermally conductive reservoir that holds phase change materials for thermal storage.

Non-template approach: As the name suggests, this involves directly synthesizing 3D graphene without sacrificial templates. Junhong Cheng and team [38] managed to highlight that with direct current plasma enhanced CVD and negative glow discharge, vertical graphene sheets can be grown on conductive substrates for instance $\mathrm{Au}$ and stainless steel. Vertical graphene patterns were designed by artificially designing the surface electric field distribution. Critical analysis of the results do revel that the carbon nanowall growth evolution comprised: nucleation, growth and interconnection of graphite nanosheets onto nanoislands and subsequently coagulation of as-grown graphite nanosheets. They reported the highest CNW growth rate within the first 1-3 min, whereas a steady thickness was observed below $10 \mathrm{~nm}$ throughout the growth [38]. Furthermore, the $\mathrm{OH}$ radicals were vital during the initial nucleation stage, however, oxidation of the CNWs was observed if the $\mathrm{OH}$ radicals were in excess. Therefore, for high crystalline CNWs, optimum feed gas relative humidity of $40 \%$ and optimum current density of $9.17 \mathrm{~A} / \mathrm{m}^{2}$ was reported [38]. These graphene patterns were then used in a field-effect transistor device for detecting low concentration gases.

\section{Assembly of Graphene Oxide (GO) Sheets}

First and foremost before the assembly of Graphene oxide/ Graphene sheets, GO solution is prepared. This is usually carried out by oxidation of $99.9 \%$ pure graphite powder in what is known as Hummer's method. The graphite is normally added to $95 \%$ sulphuric acid $\left(\mathrm{H}_{2} \mathrm{SO}_{4}\right)$ and the mixture cooled to $0^{\circ} \mathrm{C}$, followed by addition of potassium permanganate $\left(\mathrm{KMnO}_{4}\right)$ to maintain a temperature less than $20^{\circ} \mathrm{C}$. Additional steps can be carried out to ensure a pure aqueous GO solution, for example Compton et al. [39] increased the $\mathrm{GO}$ suspension to $35^{\circ} \mathrm{C}$ for 2 hours and then cooled it back to $0^{\circ} \mathrm{C}$ in an ice bath [39]. They then added $750 \mathrm{ml}$ of water with hydrogen peroxide $\left(\mathrm{H}_{2} \mathrm{O}_{2}\right)$ and left it overnight. Following this, the mixture was then washed with concentrated $1 \mathrm{M} \mathrm{HCl}$ and deionised water in order to remove the metal ion. It was then put in a centrifuge to help get rid of any remaining acid until the $\mathrm{pH}$ was 7.0. Lastly, the solid was dispersed in water making use of an ultrasonicator to finally get aqueous GO solution (Table 3 ).

\section{Self-assembly of GO through chemical reduction}

Secondly, it is useful to be aware that in a GO solution, there exists a force balance between the van der Waals forces of attraction form the basal planes and electrostatic repulsion from the present functional groups within the GO sheets [40]. On breaking this force balance (this can be achieved by changing the $\mathrm{pH}$ in the GO dispersion suspension) the addition of suitable cross-linkers [41] or any ultrasonication of the GO dispersion solution will then enhance gelation to take place [42] Therefore in a typical procedure carried out by Compton et al. [39] the GO sheets are first dispersed in a solution and followed by a series of procedures entailing gelation and reduction processes (sodium ascorbate, $\mathrm{NaHSO}_{2}, \mathrm{Na}_{2} \mathrm{~S}$ could be reducing agents added to aqueous $\mathrm{GO}$ and sonicated followed by heating to $90^{\circ} \mathrm{C}$ for 1.5 hours to produce graphene hydrogels) before carrying out freeze-drying or freezecasting and $3 \mathrm{D}$ graphene structure is obtained. These can be physically cross-linked or chemically cross-linked. Further modifications have also been experimented upon in the past for example; electrochemical reduction, metal-ion induced self-assembly and evaporation induced self-assembly.

\section{Self-assembly of GO through electrochemical reduction}

Over and above this, self-assembly of GO has also been achieved through electrochemical reduction (ErGO) [43-47]. This is more often than not used to directly fabricate electrodes. In a nutshell, a typical known procedure would involve electrochemically reducing GO on metal electrodes for example $\mathrm{Au}$ in a $3 \mathrm{mg} / \mathrm{ml}$ aqueous $\mathrm{GO}$ suspension in the presence of $0.1 \mathrm{M}$ lithium perchlorate $\left(\mathrm{LiClO}_{4}\right)$, with an applied potential of $-1.2 \mathrm{~V}$ for roughly $10 \mathrm{~s}$. Highly conductive GO sheets are deposited on the surface of electrodes and subsequently assembled into $3 \mathrm{D}$ interpenetrating networks.

\section{Self-assembly of GO through hydrothermal reduction}

Hydrothermal reductions have also been noted to reduce Graphene

\begin{tabular}{|c|c|c|c|c|}
\hline Synthesis method & Specific surface area & Pore volume & Cycling life & Applications \\
\hline $\begin{array}{c}\text { Hummer's method to produce GO, followed } \\
\text { by autoclaving with tetrahydrofuran. }\end{array}$ & $\sim 209 \mathrm{~m}^{2} / \mathrm{g}$ & $\sim 0.68 \mathrm{~cm}^{3} \mathrm{~g}^{-1}$ & $\begin{array}{l}\text { Reverse capacity of } 110 \mathrm{mAh} / \mathrm{g} \text { after } 100 \\
\text { cycles at current density of } 0.2 \mathrm{~A} / \mathrm{g}\end{array}$ & Lithium -ion batteries \\
\hline $\begin{array}{c}\text { Hummer's method to produce } \mathrm{GO} \text {, followed } \\
\text { by hydrothermal treatment in a sealed } \\
\text { reactor vessel }\end{array}$ & & & $771 \mathrm{mAg}^{-1}$ at $\mathrm{C} / 10$ rate, $73 \%$ after 30 cycles & Lithium-ion battery anodes \\
\hline $\begin{array}{c}\text { Hummer's method to produce GO, mixing } \\
\text { with } \mathrm{SnO} 2 \text {, followed by chemical reduction } \\
\text { with L-ascorbyl acid in a in an oven and } \\
\text { finally freeze dried. }\end{array}$ & $188-109 \mathrm{~m}^{2} / \mathrm{g}$ & & $\begin{array}{c}\text { Reversible specific capacity is as high as } \\
984.2 \mathrm{mAh} / \mathrm{g} \text { at a specific current of } 200 \\
\mathrm{~mA} / \mathrm{g} \text {. }\end{array}$ & Lithium-ion battery anode \\
\hline $\begin{array}{c}\text { Hummer's method to produce GO, followed } \\
\text { by autoclaving. }\end{array}$ & & & $\begin{array}{l}\text { Specific capacity of } 165 \mathrm{mAhg}^{-1} \text { and stable } \\
\text { operation of over } 80 \text { cycles }\end{array}$ & Super capacitors \\
\hline
\end{tabular}

Table 3: Showing the properties of 3D graphene structures fabricated for energy storage application. 
Oxide and induce self-assembly of GO with the help of autoclave at reasonably high enough temperatures of between $90-200^{\circ} \mathrm{C}$ and high pressures. Xu et al. [5] achieved well assembled graphene hydrogel via a one step hydrothermal treatment. These were produced by subjecting a $2 \mathrm{mg} / \mathrm{ml}$ graphene oxide aqueous dispersion to a sealed Teflon lined autoclave at $180^{\circ} \mathrm{C}$ for about half a day [47]. This was then followed by freezedrying to produce hydrogels that had well interconnected 3D porous networks and high electrical conductivity in the neighbourhood of $5 \times 10^{-3} \mathrm{~S} / \mathrm{cm}$. This is attributed to the known recovery of the present $\pi$-conjugated system of GO sheets upon the hydrothermal reduction process. On further analysing the results obtained by Yuxi. Xu et al. [5] the self-assembled graphene hydrogel exhibited different mechanical properties as the hydrothermal reduction time increased. For example, the graphene hydrogel sample with hydrothermal treatment time of 12 hours had a compressive elastic modulus of $290 \pm 20 \mathrm{kPa}$. This is in stark contrast to the self-assembled graphene hydrogel sample with hydrothermal treatment time of 1 hour that had compressive elastic modulus of $29 \pm 3 \mathrm{kPa}$ [37].

Cross-linkers: The use of cross-linkers after the fabrication of GO is crucial to the enhancement of the mechanical properties of the final $3 \mathrm{D}$ graphene structure. A cross-linker is normally added to the GO dispersion, which functionalizes the graphene surfaces and facilitates the interactions between the GO/graphene sheets. Pyrrole is one such cross linker. Vlassiouk et al. [31] were able to report how excellent mechanically strong graphene foam electrodes can be synthesised using Pyrrole as a cross-linker in the GO aqueous solution. The Pyrrole monomer $\left(\mathrm{C}_{4} \mathrm{H}_{4} \mathrm{NH}\right)$ is a weakly basic sweet smelling liquid compound that has an electron rich $\mathrm{N}$ atom that attaches on the surface of the GO sheets through-bonding and $\pi-\pi$ interactions, enhancing the binding process between the GO sheets and subsequently preventing the selfstacking of GO during the hydrothermal treatment.. The 3D G (Py) foam thus had a much larger Brunauer-Emmett-Teller surface area of $463 \mathrm{~m}^{2} / \mathrm{g}$ in comparison to the $186 \mathrm{~m}^{2} / \mathrm{g}$ of the 3D graphene foam [40]. Apart from the above mentioned Pyrrole, other chemical or physical cross-linkers have been reported by various reports. These include polyvinyl alcohol (PVA) [18], $\mathrm{FeSO}_{4}$ [42], noble metal salts- $\mathrm{PdCl}_{2}$, $\mathrm{HAuCl}_{4}, \mathrm{RhCl}_{3}$ [15], DNA [22] and amines [24]. Zhihong Cao et al. [16] reported that noble metal $\mathrm{Pd}$ can be used to facilitate the thredimensional macroassembly of single-layered graphene oxide. The GO aqueous suspension containing $\mathrm{PdCl}_{2}$ and glucose was hydrothermally treated to obtain a 3D structure. The role of glucose here is to reduce the $\mathrm{PdCl}_{2}$, and also enhance the mechanical strength - moreover, the compressive strength and compressive modulus are approximately $0.042 \mathrm{MPa}$ and $0.26 \mathrm{MPa}$ respectively. The Pd nanoparticles facilitate assembly by anchoring to the GO sheet and acting as active sites for the assembly with another GO sheet. And due to the numerous corrugations present in the $\mathrm{Pd}$-bearing $\mathrm{GO}$, this forms a porous $3 \mathrm{D}$ structure. The samples had an average conductivity of abut $2.5 \times 10^{-3}$ $\mathrm{S} / \mathrm{cm}^{-1}[15]$.

Freeze-drying: Freeze-drying is normally carried out after gelation has occurred and the reduction of the GO dispersion with a purpose of elimination any water or organic molecules from within the present pores in the 3D graphene network. This is feasible because it removes absorbed molecules without itself degrading the 3D graphene network. The hydrothermal reduction process described in the previous section can be performed in conjunction with freeze-drying/freeze-casting. In fact Xiao Xie and his team of 6 members produced 3D graphene through a hydrothermal reduction procedure followed by freezedrying [40]. They were successful in investigating the effect of freezing temperature on the porous microstructures as seen below in Figure 2.

It was observed that the mean pore size varied from a range of $10 \mu \mathrm{m}$ to $700 \mu \mathrm{m}$ with corresponding freezing temperatures ranges of $-170^{\circ} \mathrm{C}$ and $-10^{\circ} \mathrm{C}$ as seen in Figure 2 . On the other hand, the wall thickness showed a sequential increase from $20 \mathrm{~nm}$ to $80 \mu \mathrm{m}$ in the temperature ranges of $-170^{\circ} \mathrm{C}$ and $-10^{\circ} \mathrm{C}$. In addition to the above, the $0.5 \mathrm{ml}$ ammonia ( $30 \mathrm{v} / \mathrm{v} \%$ ) was carefully poured to a homogeneous GO colloidal dispersion of $20 \mathrm{ml}$ in order to alter the $\mathrm{pH}$ to a value of 10 . Following this, the GO dispersion was placed into a sealed reactor and subsequently subjected to temperatures of $180^{\circ} \mathrm{C}$ for about 20 hours to produce a Reduced GO gel block. Next, the reduced GO block was subjected to cold temperatures in a cold source with the rate of crystal growth altered by the cold source temperature. This freezing was carried out for several minutes until a solid gel block was produced. Lastly freeze drying was carried out for 48 hours to eventually obtain the $3 \mathrm{D}$ graphene sponge.

Template-assisted assembly: Another method of synthesising $3 \mathrm{D}$ graphene aerogels is by assembling GO graphene sheets around the surfaces of templates. This can be carried out by a variety of ways namely: electrophoretic deposition, dip coating, also refluxing in an autoclave and template assisted freeze drying. Apart from the Nickel foams that were earlier discussed, other templates can also be made use of in the synthesis process, for example commercially available polyurethane sponges, silica nanoparticles, polystyrene particles and textile fibres can also be used as templates.

Caixia Chi et al. managed to synthesise 3D hierarchical porous graphene aerogels (HGAs) with polystyrene (PS) particles as sacrificial templates. This involved preparing the polystyrene particles separately: firstly, styrene monomer and initiator $\mathrm{K}_{2} \mathrm{~S}_{2} \mathrm{O}_{8}$ were carefully dispersed a

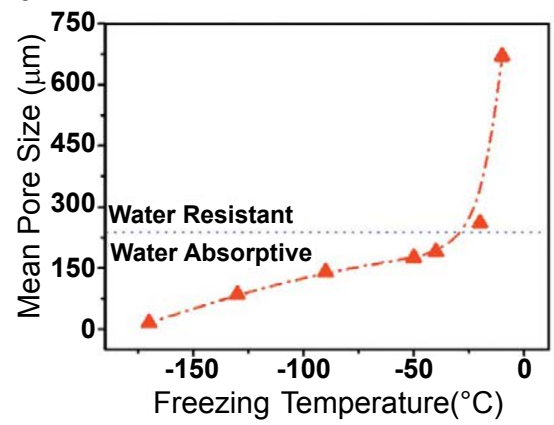

b

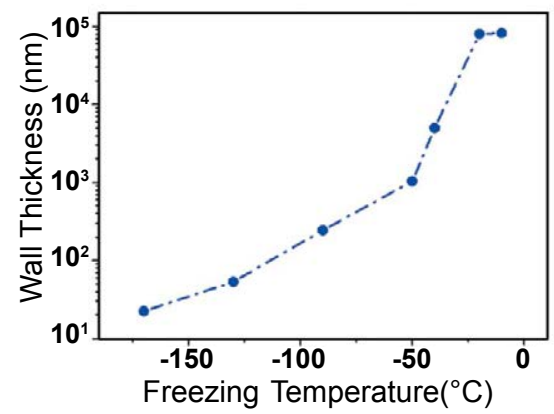

Figure 2: Showing the variation of mean pore size and wall thickness as a function of freezing temperature [24]. 
in aqueous solution and subjected to temperatures of initiation of $70^{\circ} \mathrm{C}$ under rapid stirring of $400 \mathrm{rpm}$. Polystyrene particles of varying sizes were produced by merely increasing the monomer content. Larger particles can also be produced by dispersion polymerization and treatment in $\mathrm{H}_{2} \mathrm{SO}_{4}$ to obtain sulfocated polystyrene particles. These particles together with the GO aqueous solution were then mixed thoroughly.

Following this, the GO aqueous dispersion solution was mixed with polystyrene particles in solution, as well as $30 \mathrm{mg}$ ascorbic acid was playing the role of reducing agent. Then, the mixture was sonicated for 15 minutes to dissolve the ascorbic acid and obtain a homogeneous red-brown dispersion. Consequently, the as-prepared dispersion was now subjected to temperatures of $80^{\circ} \mathrm{C}$ for a period of 1.5 hours inorder to give rise to PS/graphene hydrogels. This was immediately immersed in tetrehydrofuran in order to get rid of PS particles and obtain the HGHs. Lastly, the HGH was dialysed with ultra pure water for a period of three days and later freeze-dryed to finally give rise to the $3 \mathrm{D}$ hierarchical porous graphene aerogels. These samples were to be tested for oil-water separation and found to have a recycle rate of eight times without degradation.

\section{Properties}

It is time to investigate some of the useful properties associated with 3D graphene materials. 3D graphene materials namely; foams, sponges and aerogels all possess excellent intrinsic properties, large surface areas and pore volumes.

$3 \mathrm{D}$ graphene networks that exhibit chemical bonding within the porous structure posses better properties in comparison to the physically assembled 3D graphene structures. Let us take a look at the bilk electrical conductivity of the graphene aerogel possessing chemical bonding fabricated by Worsley et al. it has a value of $1 \mathrm{~S} / \mathrm{cm}$. This is in stark contrast to the GO hydrogel with a conductivity of $5 \times 10^{-3} \mathrm{~S} / \mathrm{cm}$ fabricated by $\mathrm{Xu}, \mathrm{Y}$, Sheng, $\mathrm{K}$ et al. or even the reduced Graphene oxide (rGO) with a conductivity value $2.5 \times 10^{-3} \mathrm{~S} / \mathrm{cm}$ fabricated by Tang, Shen, and Zhuang. We can conclude from these results in literature that the electrical conductivity of chemically bonded 3D graphene materials is roughly more than two orders of magnitude higher as compared to the $3 \mathrm{D}$ graphene materials fabricated with physical cross-linking or partial chemical bonding. On overall, in an earlier section, we were able to see the SEM micrographs which reveal the unique and very continuous well interconnected networks present in graphene foams, the advantage of this are evident in the high electrical conductivity of around $1 \mathrm{~S} / \mathrm{cm}$. It is noted that graphene aerogels have an absence of an organic cross linker. The probable explanation to this can be attributed to the favourable cross-linking between functional groups on both surface and present edges of the graphene oxide whilst the sol-gel process is taking place.

Over and above this, it is appreciated that some of the differences in properties can be attributed to the varying fabrication parameters or conditions which have an overall effect on the structural features for example, arrangement and orientation of the present graphene sheets. Graphene foams assembled with a metal template like Nickel will possess graphene sheets that have little or no overall orientation thus giving rise to an isotropic structure. However, with the case of graphene sponges, the graphene nano-sheets are stacked in a well ordered manner and in fact are nearly parallel with one another. This gives rise to anisotropic structure in graphene sponges. Moreover, it is necessary to be aware that the microstructure/macrostructure of graphene foams can easily be controlled by altering the key parameters in the preparation process. Firstly, since we are employing a Nickel foam as the catalyst and template, if we manage to alter its pore structure, we can also tune the pore size and porosity of our graphene foam sample. This in turn has an effect on the surface area. Continuing on from here the $\mathrm{CH}_{4}$ concentration or carbon source plays an important role on the sought after properties of the graphene foam for instance, if we use a higher concentration of $\mathrm{CH}_{4}$, this will increase the number of graphene layers. This in turn causes an increase in the thickness and mass of the graphene foam. On the contrary, the density and specific surface area of the graphene foam decrease with an increase in the number of graphene layers deposited. This anomaly is likely to be the reason why the framework shrinks and the $\mathrm{HCl}$ and the acetone etching is minimised.

The properties and macrostructures of graphene sponges can be adjusted by altering the synthesis conditions. For the graphene sponges manufactured by Xie et al., we can see that the pore size and pore wall thickness decreased over a region of 80 to 4000 times respectively as the freezing temperature decreased from between -10 to $170^{\circ} \mathrm{C}$. Furthermore, the pore morphology exhibited a dramatic change from the actual anisotropic lamellar structure to one that was more uniform and cellular. The mechanical properties of the graphene sponge could be altered over the freezing temperatures for example, the Young's Modulus could be varied from 13.7 to $204.4 \mathrm{kPa}$. Talking about the pore size, for value of more than $300 \mu \mathrm{m}$ it was realised that the sponge was hydrophobic; however for a pore size of less than $150 \mu \mathrm{m}$ the sponge could absorb water. It is thus important to note that altering the pore size and freezing temperatures can have an overall effect on the properties of the graphene sponge. This is why graphene sponges can be employed as efficient oil water separators.

\section{Applications}

Three-dimensional Graphene has been observed to have excellent extrinsic and intrinsic properties and this has been exploited for various applications. Discussed here are the applications in the catalysis, energy storage and conversion (super capacitors, lithium-ion batteries), oilwater absorption and sensors.

\section{Catalysts}

It has been found that due to the excellent intrinsic properties possessed by $\mathrm{GO} /$ graphene sheets in $3 \mathrm{D}$ graphene networks, they have been found to be useful for catalysis applications. These can be put to good use in real life applications and catalysis is one of the main. Let us start off with the use of 3D Graphenes as a metal free catalyst for oxidation of thioanisole. For example Marques and his team fabricated Graphene Oxide foams by hydrothermal treatment from an aqueous GO suspension at $180^{\circ} \mathrm{C}$ for 12 hours. Their findings showed an impressive catalytic activity of greater than $90 \%$ during the oxidation reaction of thioanisole. If we compare this performance to say other known metal-free catalysts like fullerenes and cyclodextrins for even 2D GO, we realise that the performance of 3D GO foams is much better. Moreover, it is highly efficient and also a reusable heterogeneous catalyst due to there being an absence of transition metals. In addition, only $11 \mathrm{wt} \%$ of 3D GO foams was used in comparison to the amount of substrate. This quantity is substantially lower than what would be needed if 2D GO foam were to be used as a catalyst. 3D graphene foams have an added advantage of being employed and showing optimum catalytic activity at room temperature. Amarojothi et al. also found GO foam to have a high catalytic activity for the acetalization of aldehydes at room temperature and it was noted that the sulphate groups present in GO brought in by Hummer's method are the primary sites for catalysis. 
It is also thus safe to say that GO is renewable because it is obtained by oxidation of Carbon which is obtained from natural Carbon sources. We also do not have to worry about contamination because there is absence of transition metals.

\section{Energy storage and conversion}

3D Graphenes have proven to be beneficial in the application of energy storage and conversion for example in the field of lithium ion batteries, solar cells and fuel cells to name a few.

\section{Super capacitors}

High performance super capacitor electrodes have been developed that are derived from 3D graphene networks and show high specific capacitance. Credit is given to Van Itoa Nguyen and Jae-Jin Shim for fabricating a three-dimensional nickel foam/graphene/ $\mathrm{NiCO}_{2} \mathrm{O}_{4}$. To start off, the NiF was immersed in GO suspension of concentration 1.5 $\mathrm{gL}^{-1}$ and with the help of electro deposition at a potential of $0.5 \mathrm{~V}$ for 10 min, $\mathrm{rGO}$ was deposited and also simultaneously reduced to graphene in order to cover graphene onto the Nickel foam. Next, a green bimetallic (NiCo) hydroxide was electrodeposited for 10 mins onto the Nickel foam that has the graphene sheets. Further preparation was carried out before placing the sample in a quartz tube and calcined at $300^{\circ} \mathrm{C}$ for 2 hours at a ramping rate of $1^{\circ} \mathrm{C} \mathrm{min}^{-1}$ to convert the hydroxide to a mesoporous $\mathrm{NiCO}_{2} \mathrm{O}_{4}$. On overall, the obtained electrode had a specific capacitance of 2260 at high current densities of $7.5 \mathrm{Ag}^{-1}$. It also had an excellent cyclic stability.

\section{Lithium-ion batteries}

A lot of scientific research is being carried out in the field of Lithium ion batteries because they are important devices for electrical storage and supply. However, the greatest challenge thus far has been achieving anode and cathode materials that exhibit the most desirable properties; of high capacity, high cycling performance and route capability. Of late, $3 \mathrm{D}$ graphene foams have proven to be a candidate that can surpass the desired material properties. Wei Wei, Shubin et al. managed to show that wrapping nano-spheres (NS) in graphene shells to give rise to core-shell structures partly alleviates the pulverization brought about by the volume changes of the metal oxide electrodes currently used. To add on, the $\mathrm{Fe}_{3} \mathrm{O}_{4} / \mathrm{NS}$ wrapped by graphene sheets and also further confined with an interconnected graphene network provides protection against any volume changes of $\mathrm{Fe}_{3} \mathrm{O}_{4} / \mathrm{NS}$ whilst undergoing the electrochemical processes. Below is a schematic of the procedure used to fabricate the $\mathrm{Fe}_{3} \mathrm{O}_{4} @ \mathrm{GS} / \mathrm{GF}$.

the synthesis method, there was an assembly of positively charged $\mathrm{Fe}_{3} \mathrm{O}_{4} / \mathrm{NS}$ and negatively charged $\mathrm{GO}$ via electrostatic interactions. This was followed by hydrothermal self-assembly of the above $\mathrm{Fe}_{3} \mathrm{O}_{4} @$
GO and GO. When used as an anode for lithium storage, a high cyclic performance of $1059 \mathrm{mAhg}^{-1}$, over 50 cycles and an excellent rate capability of $363 \mathrm{mAhg}^{-1}$ at $4800 \mathrm{mAg}^{-1}$ were obtained. On further analysing the performance of the prepared $\mathrm{Fe}_{3} \mathrm{O}_{4} @ \mathrm{GS}$ and $\mathrm{Fe}_{3} \mathrm{O}_{4}$ nanospheres (NS), it was concluded that $\mathrm{Fe}_{3} \mathrm{O}_{4} @ \mathrm{GS} / \mathrm{GF}$ had the most superior cyclic performance. There was an increasing trend of the capacity of $\mathrm{Fe}_{3} \mathrm{O}_{4} @ \mathrm{GS} / \mathrm{GF}$ in the initial 85 cycles which was unlike the rest. The underlying reason for this the reversible growth of the polymeric gel-like film by the kinetically activated electrolyte degradation (Figure 3).

\section{Absorbents}

It is known that $3 \mathrm{D}$ graphene structures can have varying pore diameters and can be tuned to have pore diameters on the nanoscale range, thus enabling 3D graphene structures to have high specific surface areas. In conjunction with these properties, 3D graphene structures are very hydrophobic, have excellent thermal stability and are mechanically strong. To add on, this has enabled them to be used as potential substitutes to conventional absorbents especially for organic contaminants and heavy metal ions. GO/Graphene foams possess excellent super absorbent properties. Moreover, they can easily be removed and recycled for repeated use. Hengchang $\mathrm{Bi}$ and group fabricated and developed 3D graphene sponge by hydrothermal treatment and freeze dryer technique. The absorption capacity of the spongy graphene to petroleum products and toxic solvents was as high as 86 times its own wright with a regeneration capacity of just more than 10 times by heat treatment. Moreover, the heat treatment yielded almost the full release of adsorbates. Lei and co-workers fabricated and developed a 3D GOF/ $/ \mathrm{Fe}_{3} \mathrm{O}_{4}$ nanocomposite for the removal of $\mathrm{Cr}$ (IV) and this resulted in a maximum absorption capacity of $258.6 \mathrm{mg} / \mathrm{g}$ and large surface area of $574.2 \mathrm{~m}^{2} \mathrm{~g}^{-1}$. Sensors

Due to the unique extraordinary properties of $3 \mathrm{D}$ graphene networks such as low mass densities, they have been used in the sensing application. Xiaochen Dong et al. used Chemical Vapor Deposition to synthesise a macroporous, highly conductive, and monolithic graphene foam for use as an electrochemical sensor to detect the concentration of dopamine. It was observed that the a sensitivity of $619.6 \mu \mathrm{AmM}^{-1}$ $\mathrm{cm}^{-2}$. A low detection limit of $25 \mathrm{nM}$ at a signal to noise ratio of 5.6 was observed. Further work in literature was carried out by Fazel Yavari et al., where they also used CVD to grow graphene foams and use them as highly sensitive gas detectors. This was possible by keeping track of their change in resistance $(\Delta R / R)$ as a function of time within a carefully controlled environment in a chemiresistor equipped with a four-probe measurement for varying analyte concentrations. A change in resistance from $30 \%$ for $1000 \mathrm{ppm}$ to $5 \%$ for $20 \mathrm{ppm}$ of $\mathrm{NH}_{3}$. Jeong Sook Ha et al. were able to use a composite of fragmented graphene

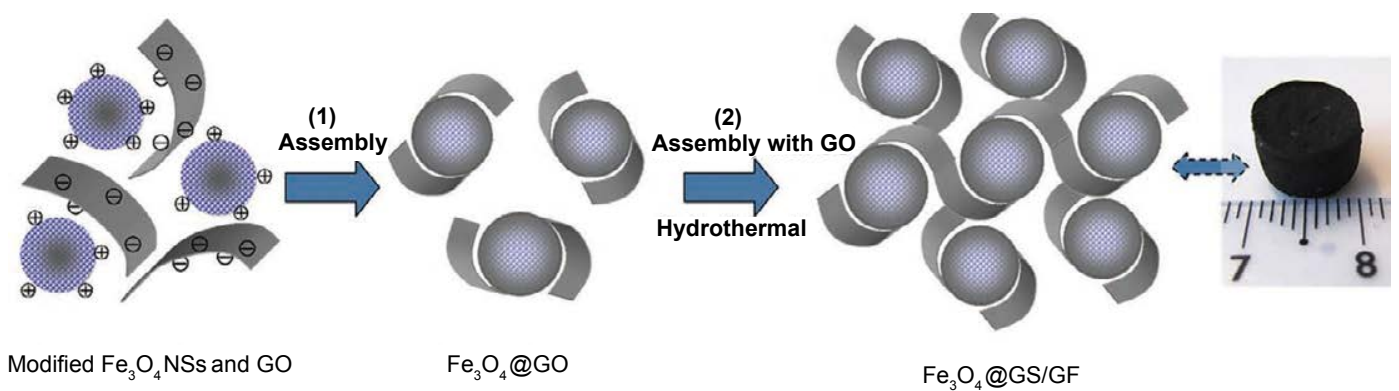

Figure 3: Fabrication process and photograph of $\left.\mathrm{Fe}_{3} \mathrm{O}_{4} @ G S / G F .1\right)$ Assembly of positively charged $\mathrm{Fe}_{3} \mathrm{O}_{4} / \mathrm{NS}$ and negatively-charged $\mathrm{GO}$ via electrostatic interactions. 2) Hydrothermal self-assembly of $\mathrm{Fe}_{3} \mathrm{O}_{4} @ \mathrm{GO}$ and $\mathrm{GO}$ [26]. 
Citation: Bagoole O, Rahman M, Younes H, Shah S, Al Ghaferi A (2017) Three-Dimensional Graphene Interconnected Structure, Fabrication Methods and Applications: Review. J Nanomed Nanotechnol 8: 438. doi: 10.4172/2157-7439.1000438

and polydimethylsiloxane (PDMS) manufactured by direct growth on Nickel foam to fabricate highly stretchable and sensitive strain sensors. They achieved a high sensitivity strain sensor of gauge factor 15 to 29 . Nonetheless, the strain sensor achieved a high stretchability of over $70 \%$ and high durability of over 10000 stretching-releasing cycles. It was observed to be of good use as a health-monitoring device since it elbow movements and pulse of the radial artery.

\section{Conclusion}

Three-dimensional graphene is a promising material for use in a wide range of applications and as such has seen a great deal of research in fields of super-capacitors, energy conservation, oil and gas to name a few. This review has made a contribution to the field of threedimensional graphene because it covers the most feasible fabrication methods of three-dimensional graphene for a variety of applications. We covered topics including Chemical Vapour Deposition, Hummer's method and freeze-drying. It is concluded that the most promising methods for future mass scale production is by the Hummer's method and subsequent reduction of Graphene Oxide to get graphene. The various applications and the motivation of three-dimensional graphene and its tremendous use for environmental remediation is fully expounded upon, with particular attention to its sorbent properties and separation of crude oil from an oil-water mixture. Three-dimensional graphene can achieve a high surface area with excellent intrinsic and extrinsic properties which are exploited for use in oil-water separation, supercapacitors, energy storage and conversion and medical research to name but a few.

\section{Future Outlook and Perspectives}

Although much advancement has been observed in the synthesis of various applications of graphene/GO-based 3D frameworks, more work needs to be done to improve the control over the Chemical Vapour Deposition process, pore size and overall porosity. Many of the fabricated 3D graphene interconnected structures have been seen to have a reasonably large pore size in the micrometer range, the downside of this is that a large pore size will lead to a decrease in the mechanical properties such as the compression modulus. The reported data was seen to have a wide spectrum of values for the pore size and porosity. A more varied choice of templates for the direct growth of well interconnected graphene structures needs to be experimented on and tried. This opens up a possibility of achieving $3 \mathrm{D}$ graphene structures of more desirable shapes and sizes to suit different applications. Moreover, templates that can withstand the high temperature environment for the pyrolysis of the carbon source during Chemical Vapour Deposition are always needed which adds to the overall costs of the CVD process. For example In addition to Nickel foam, an alloy of copper that can easily be etched could be used instead of pure copper for the CVD process.

\section{Compliance with Ethical Standards}

The authors declare that they have no conflict of interest.

\section{References}

1. Basu S, Bhattacharyya $P$ (2012) Recent developments on graphene and graphene oxide based solid state gas sensors. Sensors Actuators B Chem 173: 1-21.

2. Vadukumpully SJ, Paul N, Mahanta S, Valiyaveettil (2011) Flexible conductive graphene/poly (vinyl chloride) composite thin films with high mechanical strength and thermal stability. Carbon 49: 198-205.

3. Lee C, Wei X, Kysar JW, Hone J (2008) Measurement of the elastic properties and intrinsic strength of monolayer grapheme. Science $321: 385-388$.
4. Geim AK (2009) Graphene: status and prospects. Science 324: 1530-1534.

5. Xu Z, Li Z, Holt CM, Tan X, Wang H, et al. (2012) Electrochemical supercapacitor electrodes from sponge-like graphene nanoarchitectures with ultrahigh power density. The Journal of Physical Chemistry Letters 3: 2928-2933.

6. Wu Y, Yi N, Huang L, Zhang TS, Fang H, et al. (2015) Three-dimensionally bonded spongy graphene material with super compressive elasticity and nearzero Poisson's ratio. Nature Communications.

7. Dong X, Cao Y, Wang J, Chan-Park MB, Wang L, et al. (2012) Hybrid structure of zinc oxide nanorods and three dimensional graphene foam for super capacitor and electrochemical sensor applications. RSC Advances 2: 43644369.

8. Wang $Y$, Wu $Y$, Huang $Y$, Zhang $F$, Yang $X$ (2011) Preventing graphene sheets from restacking for high-capacitance performance.The Journal of Physical Chemistry 115: 23192-23197.

9. Yang X, Zhu J, Qiu L, Li D (2011) Bioinspired effective prevention of restacking in multilayered graphene films: towards the next generation of high-performance supercapacitors. Adv Mater 23: 2833-2838.

10. Yan J, Liu J, Fan Z, Wei T, Zhang L (2012) High-performance supercapacitor electrodes based on highly corrugated graphene sheets. Carbon 50: 21792188.

11. Chen Y, Zhang X, Yu P, Ma Y (2010) Electrophoretic deposition of graphene nanosheets on nickel foams for electrochemical capacitors. J Power Sources 195: 3031-3035.

12. Winzer T, Knorr A, Malic E (2010) Carrier multiplication in grapheme. Nano Letters 10: 4839-4843.

13. Li T, Luo L, Hupalo M, Zhang J, Tringides M, et al. (2012) Femtosecond population inversion and stimulated emission of dense Dirac fermions in grapheme. Phys Rev Lett 108: 167401.

14. Nardecchia S, Carriazo D, Ferrer ML, Gutiérrez MC, del Monte F (2013) Three dimensional macroporous architectures and aerogels built of carbon nanotubes and/or graphene: synthesis and application. Chem. Soc. Rev 42: 794-830.

15. Chen J, Sheng K, Luo P, Li C, Shi G (2012) Graphene Hydrogels Deposited in Nickel Foams for High-Rate Electrochemical Capacitors. Adv Mater 24: 45694573

16. Cao X, Shi Y, Shi W, Lu G, Huang W, et al. (2011) Preparation of novel 3D graphene networks for supercapacitor applications 7: 3163-3168.

17. Dong X, Chen J, Ma Y, Wang J, Chan-Park MB (2012) Superhydrophobic and superoleophilic hybrid foam of graphene and carbon nanotube for selective removal of oils or organic solvents from the surface of water. Chemical Communications 48: 10660-10662.

18. He Y, Chen W, Li X, Zhang Z, Fu J, et al. (2012) Freestanding three-dimensional graphene/MnO2 composite networks as ultralight and flexible supercapacitor electrodes. ACS Nano 7: 174-182.

19. Chen Z, Ren W, Gao L, Liu B, Pei S, et al. (2011) Three-dimensional flexible and conductive interconnected graphene networks grown by chemical vapour deposition. Nature Materials 10: 424-428.

20. Chabot V, Higgins D, Yu A, Xiao X, Chen Z, et al. (2014) A review of graphene and graphene oxide sponge: material synthesis and applications to energy and the environment," Energy and Environmental Science 7: 1564-1596.

21. Shahriary L, Athawale AA (2014) Graphene oxide synthesized by using modified hummers approach. 2: 58-63.

22. Paulchamy B, Arthi G, Lignesh B (2015) A Simple Approach to Stepwise Synthesis of Graphene Oxide Nanomaterial. Journal of Nanomedicine and Nanotechnology 6

23. Hanifah MFR, Jaafar J, Aziz M, Ismail AF, Rahman MA (2015) Synthesis of Graphene Oxide Nanosheets via Modified Hummers' Method and Its Physicochemical Properties. Journal Teknologi.

24. Min Z, Wen-Long W, Xue-Dong W (2013) Preparing three-dimensiona graphene architectures: Review of recent development. Chinese Physics B 22: 98105-98112.

25. Liu Z, Tu Z, Li Y, Yang F, Han S (2014) Synthesis of three-dimensional graphene from petroleum asphalt by chemical vapor deposition. Mater Lett 122: $285-288$. 
Citation: Bagoole O, Rahman M, Younes H, Shah S, Al Ghaferi A (2017) Three-Dimensional Graphene Interconnected Structure, Fabrication Methods and Applications: Review. J Nanomed Nanotechnol 8: 438. doi: 10.4172/2157-7439.1000438

Page 8 of 8

26. Vargas CSR, Zhuang HL, Huang PY, Zande VD, Arend M, et al. (2011) Softened elastic response and unzipping in chemical vapor deposition graphene membrane. Nano Letters 11: 2259-2263.

27. Ismach A, Druzgalski C, Penwell S, Schwartzberg A, Zheng M, et al. (2010) Direct chemical vapor deposition of graphene on dielectric surfaces. Nano Letters 10: 1542-1548.

28. Murdock AT, Koos A, Britton TB, Houben L, Batten T, et al. (2013) Controlling the orientation, edge geometry, and thickness of chemical vapor deposition grapheme. Acs Nano 7: 1351-1359.

29. Petrone N, Dean CR, Meric I, Zande VD, Arend M, et al. (2012) Chemical vapor deposition-derived graphene with electrical performance of exfoliated grapheme. Nano Letters 12

30. Kim K, Lee H, Lee C, Lee S, Jang H, Ahn J, et al. (2011) Chemical vapor deposition-grown graphene: the thinnest solid lubricant. ACS Nano 5: 51075114.

31. Vlassiouk I, Fulvio P, Meyer H, Lavrik N, Dai S, et al. (2013) Large scale atmospheric pressure chemical vapor deposition of grapheme. Carbon 54: 58-67.

32. Rahman MM, Younes, Ni G, Zhang T, Ghaferi AAL (2016) Synthesis and optical characterization of carbon nanotube arrays. Mater Res Bul 77: 243-252.

33. Ning G, Fan Z, Wang G, Gao J, Qian W, Wei F (2011) Gram-scale synthesis of nanomesh graphene with high surface area and its application in supercapacitor electrodes. Chemical Communications 47: 5976-5978.

34. Mecklenburg M, Schuchardt A, Mishra YK, Kaps S, Adelung R, et al. (2012) Aerographite: ultra lightweight, flexible nanowall, carbon microtube material with outstanding mechanical performance. Adv Mater 24: 3486-3490.

35. Ito Y, Tanabe Y, Qiu H, Sugawara K, Heguri SN, et al. (2014) High-Quality Three-Dimensional Nanoporous Graphene. Angewandte Chemie International Edition 53: 4822-4826.

36. Zhou M, Lin T, Huang F, Zhong Y, Wang Z, et al. (2013) Highly conductive porous graphene/ceramic composites for heat transfer and thermal energy storage. Advanced Functional Materials 23: 2263-2269.
37. Hong J, Sohn E, Park S, Park HS (2015) Highly-efficient and recyclable oil absorbing performance of functionalized graphene aerogel. Chem Eng J 269 : 229-235.

38. Bai H, Li C,Wang X, Shi G (2011) On the gelation of graphene oxide. The Journal of Physical Chemistry C 115: 5545-5551.

39. Compton OC, An Z, Putz KW, Hong BJ, Hauser BG, et al. (2012) Additive-free hydrogelation of graphene oxide by ultrasonication. Carbon 50: 3399-3406.

40. Bai H, Li C, Wang B, Shi G (2010) A pH-sensitive graphene oxide composite hydrogen. Chemical Communication 46: 2376-2378.

41. Zhou M, Wang Y, Zhai Y, Zhai J, Ren W, et al. (2009) Controlled synthesis of large-area and patterned electrochemically reduced graphene oxide films. Chemistry-A European Journal 15: 6116-6120.

42. Shao Y, Wang J, Engelhard M, Wang C, Lin Y (2010) Facile and controllable electrochemical reduction of graphene oxide and its applications. Journal of Materials Chemistry 20: 743-748.

43. Li Y, Sheng K, Yuan W, Shi G (2013) A high-performance flexible fibre-shaped electrochemical capacitor based on electrochemically reduced graphene oxide. Chemical Communications 49: 291-293.

44. Haque AJ, Park H, Sung D, Jon S, Choi S, et al. (2012) An electrochemically reduced graphene oxide-based electrochemical immunosensing platform for ultrasensitive antigen detection. Anal Chem 84: 1871-1878.

45. Sheng K, Sun Y, Li C, Yuan W, Shi G (2012) Ultrahigh-rate supercapacitors based on eletrochemically reduced graphene oxide for ac line-filtering. Scientific Reports.

46. Li B, Pan G, Avent ND, Lowry RB, Madgett TB, et al. (2015) Graphene electrode modified with electrochemically reduced graphene oxide for labelfree DNA detection. Biosensors and Bioelectronics 72: 313-319.

47. Filip J, Tkac J (2014) Effective bioelectrocatalysis of bilirubin oxidase on electrochemically reduced graphene oxide. Electrochemistry Communications 49: $70-74$. 